\title{
It's a Trust Thing: Assessing Fishermen's Perceptions of the California North Coast Marine Protected Area Network
}

Lucia Ordoñez-Gauger $^{1}$, Laurie Richmond ${ }^{1 *}$, Steven Hackett ${ }^{1}$, Cheryl Chen ${ }^{2}$

1. Humboldt State University

2. Independent Consultant

*corresponding author: Dr. Laurie Richmond, Laurie.Richmond@Humboldt.edu

*Address: Department of Environmental Science \& Management

Humboldt State University

1 Harpst Street

Arcata, CA 95521

This is the author's preprint version of the following published and copyrighted journal article:

L. Ordoñez-Gauger, L. Richmond, S. Hackett, C. Chen. (2018). It’s a Trust Thing: Assessing Fishermen's Perceptions of the California North Coast Marine Protected Area Network. Ocean \& Coastal Management. 158: 144-153.

A free version of the article is available for download until May 19, 2018 here:

https://authors.elsevier.com/a/1WotE3RKK-cJ4m

Article can be accessed here:

https://doi.org/10.1016/j.ocecoaman.2018.03.034 


\begin{abstract}
$\underline{\text { Abstract }}$
The California's Marine Life Protection Act (MLPA) is a recent high profile initiative that led to the implementation of a network of 124 marine protected areas (MPAs) encompassing $16 \%$ of state waters. The effort was conducted through six different regional processes that incorporated stakeholder and scientific involvement, ending in North Coast region. While the initiative has been described as a success in terms of implementation, there has been relatively little empirical research about social perceptions of the MPA network in order to examine whether stakeholders view the effort as successful. Our research team conducted surveys with 178 commercial and charter fishermen and held five focus groups in each of the major ports of the region in order to assess fishermen's perceptions of the California North Coast MPA network - including perceptions of the both process of implementation and potential outcomes from the network. Among fishermen, satisfaction with the overall process was low; however the level of satisfaction with the inclusion of local input and the final location of the MPAs was more divided. Levels of trust in management entities, including those who implemented the MPA network, were low. Additionally, in focus group discussions, fishermen described several perceived shortcomings of the process, including an overall "top down" approach, a failure to consider the local context, and the appearance of being dismissive of fisherman perspectives. In terms of outcomes, fishermen overwhelmingly did not believe that the MPA network would improve ocean health or their income from fishing. Qualitatively, fishermen reported that while they were experiencing some minor adverse effects from the MPA network, overall they did not believe that socioeconomic impacts on the fishing industry from the MPA network would be substantial. Many expressed relief that the location of MPAs avoided many important fishing grounds. Trust emerged as an important variable. For example, the reported level of trust by fishermen in the entity that implemented the MPA network had a statistically significant correlation with their level of satisfaction with the overall process, including the final location of the MPA network. Findings complicate initial assessments of the MLPA implementation process as an overall success, and highlight the importance of trust to building successful and lasting marine conservation initiatives.
\end{abstract}

Key Words

Marine protected area, perceptions, human dimensions, trust, Marine Life Protection Act, California 


\subsection{Introduction:}

Marine protected areas (MPAs) are designated areas of the ocean where human activities, primarily fishing, are prohibited or limited. Often times the main objective of MPAs is to protect spawning and nursery grounds and re-build fish populations, with the hopes that fish and larvae will eventually 'spill over' to the surrounding, fishable areas (Boersma \& Parish 1999; Sumaila et al. 2000; Wolff 2015). Since the 1992 Convention for Biological Diversity set a target for 10\% of the world's oceans to be designated as MPAs by 2010 (McCay \& Jones 2011), there has been a substantial increase in the popularity, use, and study of this type of marine management (Caveen 2014, Conway \& Pomeroy 2006; Hart 2009; Richmond \& Kotowicz 2014; Voyer, Gladstone, \& Goodall 2012). Additionally, there has been a growing attention to the human dimensions of MPAs as scholars and practitioners began to realize the important role that stakeholder perceptions and social context can play in an MPA's social and ecological success (Webb et al. 2004; Leleu et al. 2012; Eagles et al. 2013; Bennett 2016).

A current high profile example of MPA implementation is the state of California's Marine Life Protection Act (MLPA), one of the most ambitious statewide efforts at present with its large network design of 124 MPAs incorporating 16\% of state waters (Chen \& Carr 2015). There are many examples of literature reporting on the initiative's success, with some emphasis on the process’s participatory approach (Lieberknecht 2008, Gleason et al. 2010; Fox et al. 2013; Kirlin, Caldwell, \& Gleason 2013; Sayce et al. 2013). Publications by managers involved assert that "the general process design ensured that knowledgeable stakeholders with direct interests in ocean resources had a central role in shaping outcomes and were well informed" (Fox et al. 2013:21), and that "By most measures, these MPA network planning efforts can be deemed a success” (Gleason et al. 2010:54). The definition of success used in these works, however, appears to be specific to management objectives such as effective statutes, adequate funding, and support from top state officials (Kirlin et al. 2013). Such success measures do not necessarily incorporate ecological effectiveness or social acceptability. MLPA process organizers conducted internal assessments of stakeholder participation early in the process in order to learn lessons for the process moving forward (Raab 2006; McCreary \& Poncelet 2006). However, few outside researchers have gathered empirical information about stakeholder perceptions of the MLPA planning process in order to assess whether stakeholders such as fishermen ${ }^{1}$ view the process and their participation as successful. Additionally, there has been very little empirical research about the human dimensions of the MLPA planning process in the North Coast of California - the last region of the state in which MPAs were designated.

As a part of the MLPA initiative, California developed and funded a monitoring program to evaluate social and ecological outcomes from the network - starting with baseline monitoring that was completed in 2017. This paper draws information from a larger, state-funded study to assess the baseline socioeconomic conditions of California North Coast's fishing communities in relation to MPA formation (Hackett et al. 2017). As a part of this mixed-methods study we conducted survey interviews with 178 commercial fishermen and commercial passenger fishing vessel (CPFV) operators in the region and convened five focus group conversations in each of the major ports. While the larger study gathered an array of socioeconomic data, this paper focuses on data collected regarding fishermen's perceptions of the MPA network. The North

\footnotetext{
${ }^{1}$ The term 'fishermen' is used to denote people who fish. Amongst those in the North Coast fishing community this is the preferred term regardless of gender.
} 
Coast MPA network was fully implemented in 2012 and interviews were conducted in 2014, so we were able to assess fishermen's perceptions of initial impacts from the network. The overarching goal of this paper is to examine fishermen's perceptions of the MPA network in order to speak to conversations about the relative success of the MLPA implementation effort from a social standpoint. To achieve this research goal we seek to address three key questions:

(1) What are fishermen's perceptions of the process through which the North Coast MPA network was implemented and, in particular, efforts to incorporate local participation?

(2) What are fishermen's perceptions of the potential impacts or outcomes from the implementation of the MPA network?

(3) What factors might be driving fishermen's perceptions of the MPA network?

Results of this study can be applied to future adaptive management of the North Coast MPA network as well provides insights for other emerging MPA design and planning initiatives.

\subsection{Theoretical Framework: Perceptions, Trust, Participation, and MPA Success}

Socioeconomic factors have traditionally been considered secondary to biological factors when designing marine reserves (Scholz 2004; Stewart \& Possingham 2005; Klein et al. 2008; McCay \& Jones 2011). Many scholars now agree, however, that evaluating the success of an MPA should be reflective of both social and biological factors (Boersma \& Parrish 1999; Sumaila et al. 2000; Christie 2004; Klein et al. 2008; Masud \& Kari 2015). Social factors including stakeholder engagement; perceptions of process legitimacy; equitable sharing of benefits and impacts; and conflict resolution mechanisms have been identified by scholars as important to the social and ecological success of MPA networks (see NRC 1997; Badalamenti et al. 2000; Pollnac 2001; Christie 2004; Lundquist \& Granek 2005; Osmond, Airame, \& Caldwell 2010; McCay \& Jones 2011; Voyer et al. 2012; Chen \& Carr 2015). Social perceptions or "the way individuals observe, understand, interpret and evaluate" various experiences, policies and outcomes (Bennett 2016:4), has become an accepted form of evidence for evaluating the success of conservation initiatives such as marine protected areas (Webb et al. 2004; Christie 2005; McClanahan et al. 2005; Dalton et al. 2012; Leleu et al. 2012; Bennett \& Dearden 2014; Cinner et al. 2014). Scholars highlight how perceptions data can reveal important information about social impacts, social acceptability, and the legitimacy of marine conservation initiatives (Bennett 2016; Lockwood 2010; Eagles et al. 2013; Bennett \& Dearden 2014). Within this literature, stakeholder perceptions are recognized as an important indicator of the social success of a conservation initiative such as MPAs; meaning persistent negative perceptions of MPAs (including the process through which they were implemented) can indicate a lack of success on social measures.

Scholarship on MPA implementation and success consistently highlights the importance of incorporating participation into the planning process (Scholz et al. 2004; Dalton et al. 2012; Sayce et al. 2013). Research reveals that this can increase ecological and social success when applied to MPA planning and governance (Dalton 2005; Pollnac et al. 2001; Jentoft et al. 2007; Lundquist \& Granek 2005). Emphasis on participation may be linked to long-standing findings about procedural justice from the field of social psychology. Procedural justice is the concept of fairness in governance or decision-making processes. Research in the area has coalesced around a concept called the "voice effect," which holds that "the opportunity to present information 
relevant to a decision enhances judgements of fairness of the decision-making process" (Lind et al. 1990, p 952). Lind et al. (1990: 952) note that the voice effect is "probably the best documented phenomenon in procedural justice research," a finding that has been confirmed in numerous studies conducted in laboratory and field settings (e.g. Deutsch 2000, Folger 1977, Lind et al. 1990, Lind \& Tyler 1988). Some research, however, suggests the voice effect may not apply in all settings (Bauman \& Skitka 2009). In an MPA context, the voice effect suggests that MPA implementation processes that include opportunities to public participation would be more likely to be judged as fair.

Research is also providing insight into how different dimensions of trust play a role in resource management. Distrust has been identified by several studies as an obstacle to effective environmental management, and trust has been identified as a prerequisite to successful conflict resolution (Hough 1998; Davenport et al. 2007; Hartley \& Robertson 2008; Devine-Wright 2010; Carr 2012; Smith et al. 2013; Stern \& Coleman 2014). Trust is also recognized as an important component of social capital, described as "social relations that have productive benefits” (Claridge 2004, p.1) (Woolcock 2001; Dasgupta 2009; Siegler 2014). While there has been research examining trust in the context of fishing communities (Johnson 2010, Hartley \& Robertson 2006, Hartley \& Robinson 2008), stakeholder trust remains an understudied area in relation to MPA formation and management. In this study we consider both quantitative and qualitative measures of stakeholder trust in the context of MPA formation in California's North Coast region.

\subsection{Setting \& Background}

The planning and design of the California MPA network was a long and controversial process, costing \$38 million and taking 13 years to be implemented (Fox 2013). New conservation goals, long-standing concerns about California's marine ecosystems, and the lack of a coherent process or network for MPAs in the state led the state legislature to enact the MLPA in 1999 (Chen \& Carr 2015). There were two unsuccessful attempts to implement the MLPA from 2000 to 2002. The first implementation failure was due to exclusion of stakeholders and a negative public reaction, while the second failure due to high costs and planning challenges (Osmond et al. 2010; Kirlin et al. 2013). After MLPA implementation was put on hold indefinitely due to California's financial crisis, in 2004 state policymakers supported the use of private charitable funding to implement the MLPA and thus create a statewide MPA network (Fox 2013).

This funding arrangement was formalized in a 2004 memorandum of understanding (MOU) between the California Natural Resources Agency, California Department of Fish and Game (since then renamed the California Department of Fish and Wildlife), and the Resources Legacy Fund Foundation (RLFF). This MOU established a public-private partnership known as the Marine Life Protection Act Initiative (MLPAI) (Fox 2013). After the formation of the MLPAI, the planning and implementation process took roughly seven years. The process was piloted on California's Central Coast region, and then applied throughout the remaining coastal regions of the state. The North Coast region was last of five coastal regions to develop MPAs, with its MPA network fully implemented in December 2012. The North Coast's MPA network includes 27 MPAs of four types, each with different levels of fishing restrictions, together covering over 137 square miles of water. The region is home to six key port groups (Figure 1). 
Because of past MLPA implementation failures associated with lack of stakeholder engagement and what was seen by some stakeholders as a top down planning process, the MLPAI included specific components for participatory planning (Fox 2013). These included Regional Stakeholder Groups (RSGs), a Science Advisory Team (SAT), and a Blue Ribbon Task Force (BRTF). The RSGs included resource users, environmental groups, tribal representatives, and other community members that were selected for each region (CDFW 2018).

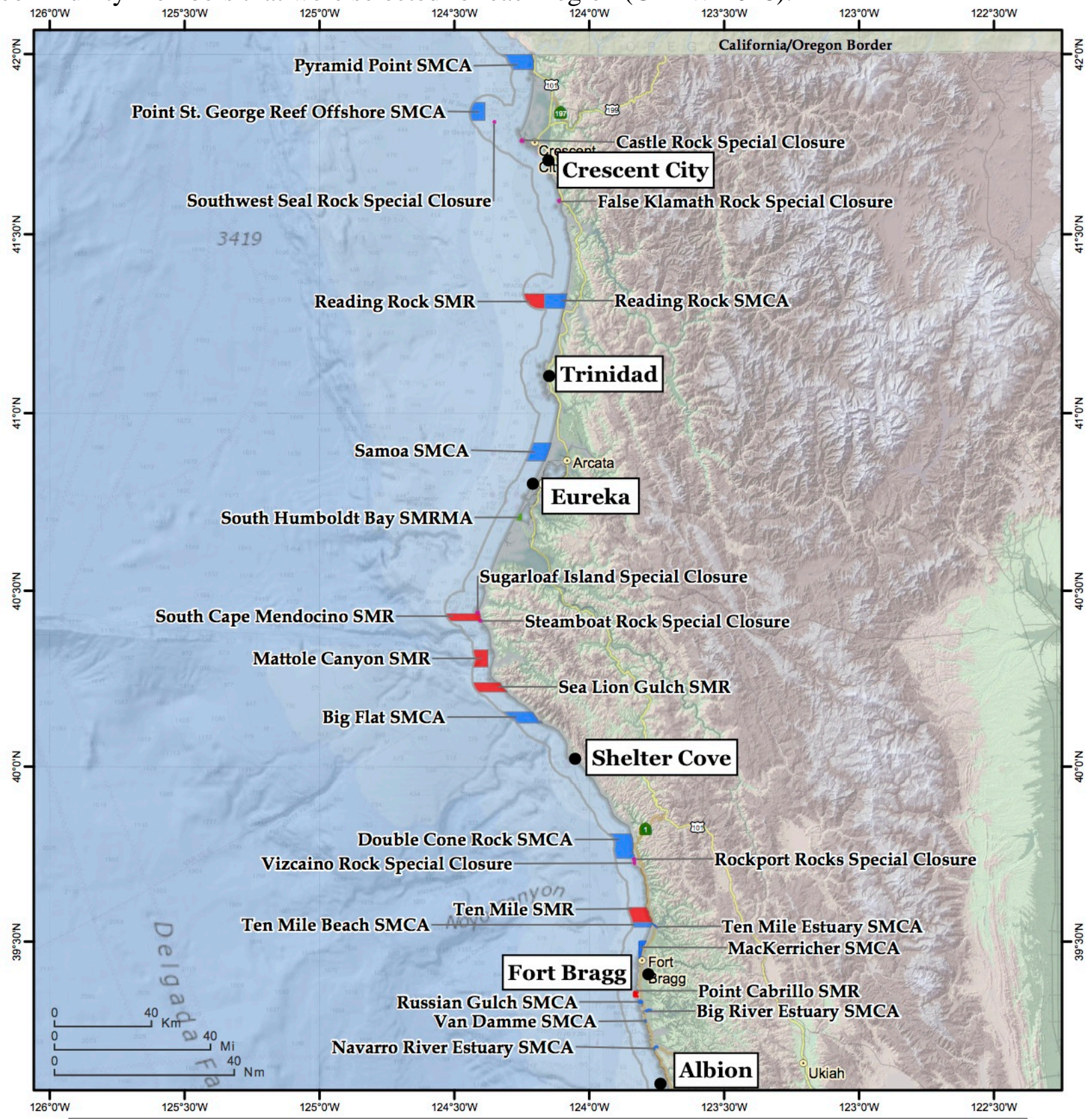

Figure 1: Map of North Coast MPAs and project study region, labeled with project ports of interest (Source: CDFW 2013). Closures are predominantly State Marine Reserves (SMR), seen in red, or State Marine Conservation Areas (SMCA), seen in blue.

RSG members were instructed to develop stakeholder MPA network proposals that met SAT science guidelines and goals. The SAT was composed of members from the scientific 
community from public and private institutions. Their task was to generate the scientific MPA guidelines and goals, and to review any RSG alternative proposals based on those guidelines. The BRTF was composed of seven individuals selected by the California Natural Resources Agency for their knowledge, public policy experience, and diversity of professional expertise. The BRTF provided direction for the expenditure of MLPAI budget funds, and made recommendations for the final layout of the MPA network in each area (CDFW n.d.; Kirlin et al. 2013). BRTF recommendations were then sent to the California Fish and Game Commission (CFGC), where minor final modifications to the proposals could (and in some cases were) be implemented, after which the MPA designations and regulations became law. All representatives in RSGs, the SAT, and the BRTF were volunteers, and collectively donated hundreds of hours of their time to participate (Gleason et al. 2013). The MLPAI had several paid staff members who assisted with the planning and implementation of the process. The MPA planning and implementation was done region by region sequentially, allowing process organizers to learn lessons from each region and to apply it going forward.

In each region, a specific RSG was formed through a public nomination process. RSG members were chosen to represent a variety of interest groups including commercial fishermen, recreational fishermen, Tribes, non-consumptive users, local government officials, and environmental groups (CDFW 2018). RSG members were to work together to create MPA network proposals that adhered to the scientific guidelines established by the SAT. MPA network proposals went through several iterations. RSG members were encouraged to negotiate and merge their proposals with each iteration to both minimize the number of proposals and to gain as much RSG agreement as possible before presenting the proposed MPA networks to the BRTF. In all regions except the North Coast, the RSG put forward multiple competing proposals for the network design. The BRTF reviewed proposals along with the evaluation of how well each proposal met science guidelines, and developed a preferred alternative that often combined aspects from multiple RSG proposals. In all cases the CFCG adopted the BRFT preferred alternative with occasional minor modifications.

Applying lessons learned from other regions, the North Coast RSG was unique in that the various interests worked together to develop a single consensus proposal for MPA locations in the region. Stakeholders from the North Coast began self-organizing before the MLPAI came to the region (RSG members, personal communication, 2012). After substantial negotiation, the North Coast RSG developed a unified proposal composed of MPA locations that all interest groups could support and, unlike other regions, the proposal did not conform to all the MLPAI science guidelines for size, spacing, and habitat representation. Deviations from the science guidelines tended to be in favor of fishermen interests, keeping MPAs out of areas used for transit near key fishing ports, as well as out of some areas that were considered important fishing grounds. Part of the rationale for these deviations was safety, as MPAs near ports might require fishermen to transit longer distances in hazardous conditions that oftentimes occur in North Coast waters. The BRTF and the Fish and Game Commission accepted and enacted this unified proposal with only a few small modifications.

\section{$\underline{4.0 \text { Methods }}$}

Data used in this study were collected as a part of a larger effort to assess the baseline 
socioeconomic conditions and initial changes following the implementation of the MPA network in the California North Coast region. A detailed description of the methods used along with a list of survey questions can be found in the report for that project (Hackett et al. 2017). The methodology for this paper was composed of three key elements: the development of a fisherman advisory council (FAC), an in-person survey, and focus group discussions held in each port. All focus group and survey data was collected during a field season between May and October 2014.

\subsection{Fisherman Advisory Council}

Early in the project we developed an advisory council composed of eight fishermen from throughout the region. Members of the FAC were chosen with an effort to gain representation from all fishing ports, all fisheries of interest, and a variety of operation sizes. The FAC was involved throughout the life of the project. They helped to design and pilot the survey tool before implementation, while also acting as local points of contact with potential participants throughout the field season. When data analyses were complete, FAC members provided feedback on the results to help us understand why certain patterns were occurring, and to ensure that the data accurately reflected the conditions in the region. This form of community outreach ensured direct input from resource users while mitigating tensions surrounding the dominant perception of surveys as research tools oftentimes working against fisherman interests.

\subsection{Survey}

A team of five field researchers conducted one-on-one in-person survey interviews with 178 commercial and CPFV fishermen in the North Coast region. Given the near-shore location of the MPA network, we focused on participants from the three commercial fisheries most likely to be affected by MPA implementation: Dungeness crab, urchin, and nearshore finfish -- a complex of 19 species (mainly rockfish) split into five different gear-market categories. While we did not specifically target salmon fishermen, we did collect information about the salmon fishery from participants in the other fisheries who also fished salmon. Through a non-disclosure agreement with CDFW we obtained contact information for all registered commercial license holders who made landings in the target fisheries, as well as for those who operated CPFV vessels in 2013 in any of the six North Coast region's fishing ports. The research team contacted every eligible individual on the list for possible participation in the study. Some individuals refused and others were difficult to get a hold of due to their fishing schedules. As this is a novel dataset we were unable to test for non-response bias. However, a comparison of respondent data with overall landings data reveals that our sample was generally representative of the population in terms of the composition of fisheries targeted and revenue stratifications (how much individuals made in total fish landings in 2013). Interviews were scheduled with vessel captains or owners-crew members did not participate in the survey.

The survey included three main components: questions related to fisherman perceptions of the ecology and management of the MPA network (the focus of this paper); questions related to the basic socioeconomic conditions of fishermen such as demographic data, costs, and reliance on income from fishing; and a mapping component where fishermen used a mapping tool to draw areas in the ocean most important to them. Survey interviews lasted from 30-120 minutes and were conducted on a location of interest to the respondent such as a restaurant, community 
center, or fishing vessel.

\subsection{Focus Groups}

\begin{tabular}{lcl} 
Port: & \# of Participants: & Date: \\
\hline Fort Bragg & 6 & $7 / 2 / 14$ \\
Shelter Cove & 4 & $6 / 12 / 14$ \\
Eureka & 10 & $7 / 11 / 14$ \\
Trinidad & 5 & $8 / 6 / 14$ \\
Crescent City & 5 & $7 / 28 / 14$ \\
TOTAL: & 30 & ---
\end{tabular}

Table 1: Date, port, and number of participants in each focus groun discussion.

We collected qualitative data from five focus groups held in each major port (Table 1). Focus groups were composed of 4-10 key informants who represented a variety of fisheries and operation sizes. After each survey, participants were invited to join their port's focus group if they were interested. Those who expressed interest were recruited to be a part of the focus group, and an effort was made to recruit individuals represented a variety of fisheries, size of operation, and age ranges. Focus group discussions were aimed at gaining a contextual understanding of the MPA network. The conversations were semi-structured; the leader would ask questions surrounding a few set topics of themes and then allow the conversation among participants to flow. Topics included: perceptions of management and the MPA network (the focus of this paper), local knowledge, and the historical context of each port (see: Hackett et al. 2017).

\subsection{Data Analysis}

Analysis of survey data results was conducted in SPSS, with specific hypotheses tested using the Kruskal-Wallis H-test. Because none of the values were normally distributed, only mean ranks were used for the test analysis. A Mann-Whitney U-test was used for post-hoc analysis on mean rank values, with output based on the Legacy Procedure (SPSS, 2016). Focus group conversations were recorded and transcribed. Analysis of that qualitative data was conducted with Atlas.ti. After a review of the conversations, the project team developed a list of seven key themes and the transcript data was coded for those themes. The analysis for this paper focuses on two key themes: fishermen perceptions of the process through which the MPA network was implemented (the process could include anything from the inception of the idea of the MPAs, to the passage of the MLPA, to the final rule that put the North Coast MPA network in effect) - and fishermen perceptions of potential impacts or outcomes from the MPA network which could include socioeconomic outcomes as well as ecological changes.

\section{$\underline{5.0 \text { Results }}$}




\subsection{Survey Results}

\subsubsection{Response Rates and Demographics}

A summary of survey responses and demographics can be found in Table 2. Overall, we interviewed 163 of the 349 registered commercial fishing license holders with landings in our three fisheries of interest, yielding an overall response rate of $47 \%$. The combined landings of our commercial fishing respondents represented more than $45 \%$ of the revenue in each target fishery on the North Coast (Dungeness crab 46.6\%, nearshore finfish 86.9\%, sea urchin 53.5\%). We also interviewed 15 out of 25 CPFV operators within the region, yielding a response rate of $60 \%$. The average age of respondents was 54 , and $62 \%$ of respondents were over the age of 50 . Only four respondents were female. In terms of prior participation in the MPA planning process, there was a high rate of variability, with some respondents indicating they were heavily involved (over 100 days of participation), and others with little to no participation. On average individual respondents participated in the process for 35 days with a standard deviation of 53 days. If the few individuals who reported more than 100 days of participation $(n=3)$ are removed, the average participation among respondents dropped to only 6.9 days. $80 \%$ of respondents reported participating in the MPA planning process for at least one day.

\begin{tabular}{rcccccc} 
Home port: & Comm. & CPFV & Total & $\begin{array}{c}\text { Age } \\
\text { (mean) }\end{array}$ & $\begin{array}{c}\text { Days } \\
\text { (molved }\end{array}$ & $\%$ Male \\
\hline Crescent City & 37 & 0 & 37 & 54.5 & 7.4 & $94.6 \%$ \\
Trinidad & 10 & 4 & 14 & 47.9 & 4.6 & $100 \%$ \\
Eureka & 46 & 4 & 50 & 49.05 & $6.1^{* *}$ & $96 \%$ \\
Shelter Cove & 9 & 2 & 11 & 44.05 & 4.1 & $100 \%$ \\
Fort Bragg & 43 & 5 & 48 & 52.4 & $10.1^{* *}$ & $100 \%$ \\
Albion & 3 & 0 & 3 & 62.3 & $8.5^{* *}$ & $100 \%$ \\
Other & 15 & 0 & 15 & 44.8 & 2.7 & $100 \%$ \\
North Coast Total: & 163 & 15 & 178 & 48.95 & $6.86^{* *}$ & $98 \%$
\end{tabular}

Table 2: Survey responses and demographics by home port. * Respondents indicated their home port on the survey, many commercial fishermen had landings in multiple ports. "Other" represents fishermen who had 2013 landings in the region but were home ported out of the region, some even out of state. ${ }^{* *}$ Adjusted mean with exclusion of outliers with $100+$ days of involvement $(n=3)$.

\section{Perceptions of the MPA Network}

Overall, 73\% of commercial fishermen and 73\% of CPFV operators indicated that the MPA network had affected their fishing in some way. The impacts appeared to be clustered around only a handful of the 26 MPAs in the network, however. For commercial fisheries, only 8 of the 26 MPAs had more than 10 fishermen (6.5\%) report a direct impact. For CPFV fisheries, only 4 
MPAs had more than one fishermen (6.5\%) report a direct impact, and 14 had no CPFV operators report a direct impact (Hackett et al. 2017).

Satisfaction with the overall process to implement the MPA network was low. A total of $82 \%$ of respondents indicated they were dissatisfied, very dissatisfied, or neutral with the process (Figure 2). Respondents were more likely to be strongly dissatisfied (21.4\%) than strongly satisfied (1.3\%) with the MPA process. Responses were divided more equally regarding satisfaction with local input to the process (37.1\% overall dissatisfied, 27\% neutral, 35.9\% overall satisfied) and the spatial locations of the MPAs (38.2\% overall dissatisfied, 30.1\% neutral, 31.8\% overall satisfied).

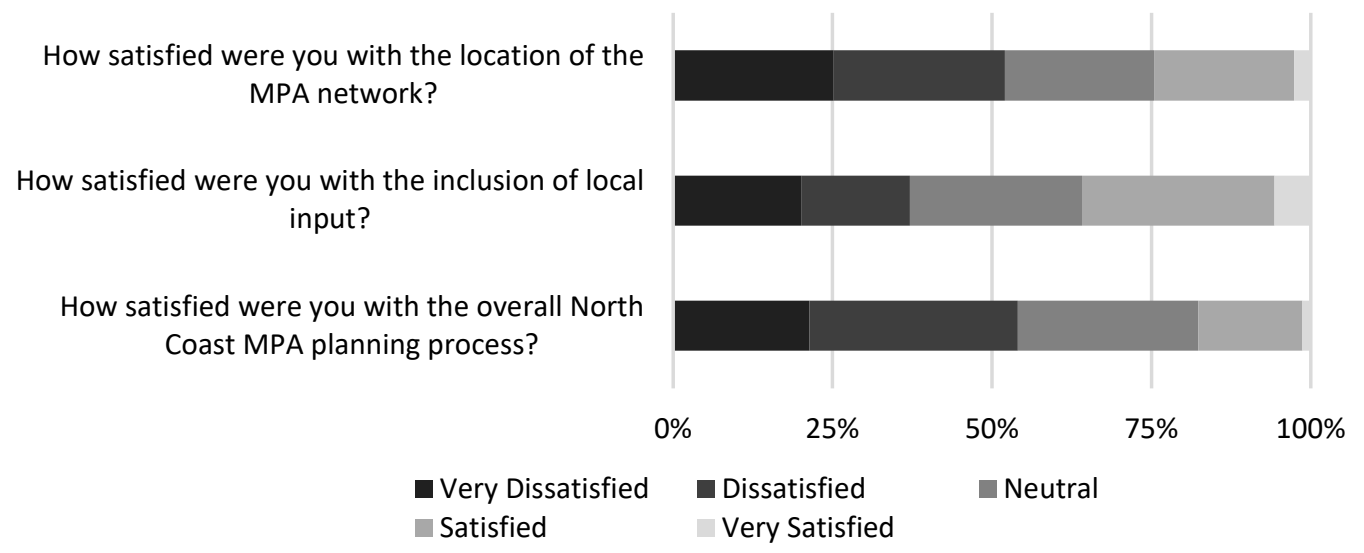

Figure 2: Responses to questions gauging participant levels of satisfaction with various aspects of the MPA network and process.

We also asked respondents to rank their level of agreement with a series of statements about potential benefits from the MPA network (Figure 3). The majority of respondents disagreed or strongly disagreed with the statement that the MPA network would improve overall ocean health (66\%) and with the statement that the network would improve fishermen's net income from fishing (73.3\%). A majority of respondents agreed or strongly agreed with the statement that enough was being done to protect and enhance marine environments before MPAs were implemented (61.5\%). The North Coast MPA network will improve overall
ocean health

Overtime, the North Coast MPA network will improve my net income from fishing

Enough is being done to protect and enhance marine environments already

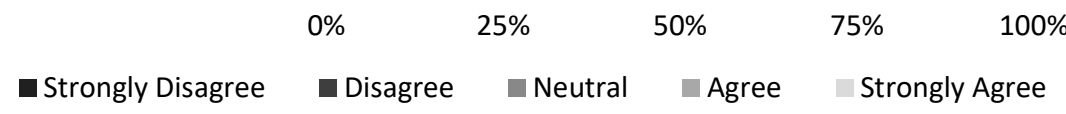

Figure 3: Responses to questions gauging participant levels of agreement with statements related to the outcomes or effects of the MPA network.

\subsubsection{Trust}


The study evaluated fishermen's level of trust in eight different entities connected to the management of marine resources on the North Coast. We created a series of statements reading "I trust [management entity]", that participants ranked their level of agreement with on a Likert scale ranging from strongly disagree (1) to strongly agree (5). Figure 4 shows the results from these questions, depicting the mean level of trust reported for each entity.

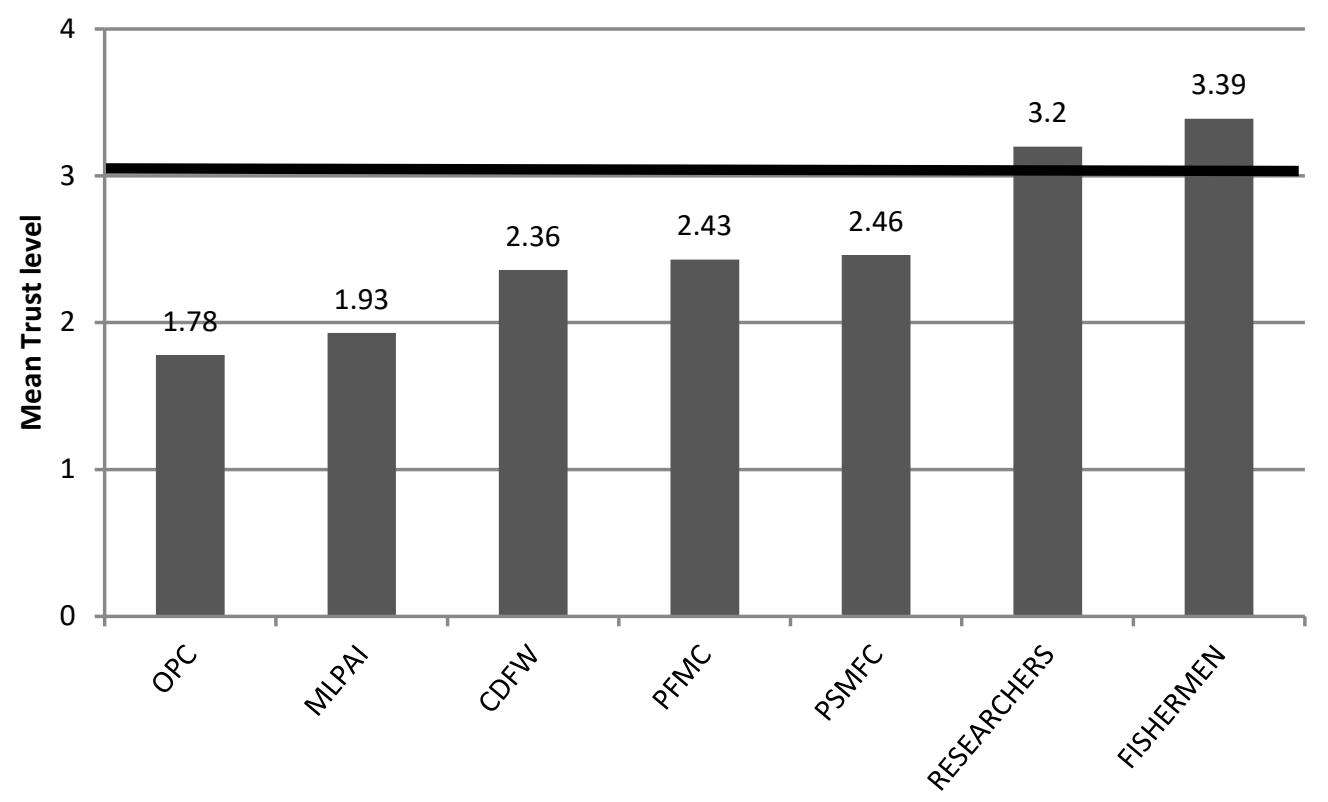

Figure 4: Respondents were asked to rank their level of agreement with the statement: “I trust xx management entity" on a scale of 1 to 5 from strongly disagree to strongly agree. On the chart, 1 represents very low trust, 3 is neutral (neither trust nor distrust) and 5 very high trust. The neutral line is shown in dark black. OPC = California Ocean Protection Council; MLPAI = Marine Life Protection Act Initiative; CDFW = California Department of Fish and Wildlife; PFMC Pacific Fishery Management Council; PSMFC = Pacific States Marine Fisheries Commission; Researchers = University researcher; Fishermen $=$ other fishermen.

Results show that the level of fisherman trust towards management and other entities is quite low in the California North Coast region. Only two of the entities - university researchers and other fishermen - had a mean level of trust above neutral, but neither was particularly high. Three state and federal management entities (CDFW, Pacific Fishery Management Council (PFMC) and Pacific States Marine Fisheries Commission (PFMC)) garnered moderately low levels of trust. The two entities with the lowest levels of trust were the hybrid public-private Marine Life Protection Act Initiative (MLPAI) that led the process of implementing the MPA network, and the State of California's Ocean Protection Council (OPC). The OPC is a non-regulatory group that was created "to improve integration of marine resource policy and articulation with related state and federal policies" (Kirlin et al. 2013:5). It is possible that some of the low levels of trust could be linked to confusion about the OPC and what it does $-16.4 \%$ of respondents were unfamiliar with the OPC.

4. Statistical Analysis 
We used non-parametric testing to examine if particular variables may be associated with responses to questions related to the level of satisfaction with three aspects of the MPA network: the planning process overall, the inclusion of local input in the planning process, and the final location of MPAs in the network. We did not observe statistically significant differences in responses to these questions based on home port or fisheries of participation. Additionally, we did not observe a statistically significant relationship between responses to these questions and age of participants, years of experience in the fishery, or number of days participating in the MPA planning process (see: Ordoñez-Gauger 2015 for details). Testing with the Kruskal-Wallis H-test did reveal statistically significant relationships between respondent levels of trust in the MLPAI and their levels of satisfaction with the MPA process and the locations of the closures. Respondent level of satisfaction with the overall MPA process also had a significant relationship to levels of satisfaction with the locations of the closures (Table 3).

\begin{tabular}{|c|c|c|c|c|c|}
\hline Variable 1 & Variable 2 & $x^{2}$ & P-value & Mean Ranks & $\begin{array}{c}\text { Mann-Whitney U Post- } \\
\text { Hoc }\end{array}$ \\
\hline $\begin{array}{l}\text { Trust level } \\
\text { MLPAI }\end{array}$ & $\begin{array}{l}\text { Satisfaction } \\
\text { MPA process }\end{array}$ & 20.317 & 0.000 & $\begin{array}{l}\text { Distrust }=\mathbf{6 6 . 3 1} \\
\text { Neutral }=92.32 \\
\text { Trust }=109.08\end{array}$ & $\begin{array}{l}U=311 \\
p=0.00\end{array}$ \\
\hline $\begin{array}{l}\text { Trust level } \\
\text { MLPAI }\end{array}$ & $\begin{array}{l}\text { Satisfaction } \\
\text { MPA locations }\end{array}$ & 12.628 & 0.002 & $\begin{array}{l}\text { Distrust }=73.71 \\
\text { Neutral }=83.29 \\
\text { Trust }=\mathbf{1 1 7 . 1 5}\end{array}$ & $\begin{array}{l}U=362 \\
p=0.00\end{array}$ \\
\hline $\begin{array}{l}\text { Satisfaction } \\
\text { MPA process }\end{array}$ & $\begin{array}{l}\text { Satisfaction } \\
\text { MPA locations }\end{array}$ & 41.098 & 0.000 & $\begin{array}{c}\text { Dissatisfied }=\mathbf{5 9 . 9 2} \\
\text { Neutral }=95.38 \\
\text { Satisfied }=\mathbf{1 1 3 . 4 3}\end{array}$ & $\begin{aligned} U & =428.5 \\
p & =0.00\end{aligned}$ \\
\hline
\end{tabular}

Table 3: Because none of the values are normally distributed only mean ranks will be used for this test analysis. MannWhitney U-test was used for post-hoc analysis on bold mean rank values, with output based on the Legacy Procedure.

\section{Focus Group Results}

\subsubsection{Perceptions of Impacts and Outcomes}

When discussing potential effects of the MPA network on their livelihoods, many participants noted that while they were experiencing some minor adverse effects from the MPA network, they were relieved that the impacts from the network were not as severe as they had expected when the process began. The common wisdom among the respondents from fishing community was that most of the MPAs in the North Coast region were placed in relatively less important fishing grounds. As one fisherman put it, "so the area they ended up taking was the area the least contested, that we didn't really fish in much anyway” (Trinidad fisherman, focus group, 2014). When reflecting on the impacts another fisherman said, "to me, I know it hurts a few people but it could have been a lot worse” (Crescent City fisherman, focus group, 2014). 
Participants cautioned that the moderate level of impacts from this MPA network should not be taken as a sign that more MPAs should be added. As more MPAs or MPAs in different locations could have substantial cumulative impacts on already declining fishing communities. Several fishermen stated that MPA locations proposed by planners early in the process could have had devastating effects on local fisheries. A proposed MPA near the rural fishing community of Shelter Cove, for example, might have had profound effects on their small-scale commercial and subsistence fisheries. In a focus group, one Shelter Cove fisherman (2014) said, "I was scared the hell out of it at first, right? I mean, the original plan just cut this whole area off.”

\subsubsection{Perceptions of the Process}

Across the focus group conversations, fishermen expressed admiration for the leaders in their industry who participated in the MPA process and engaged in the stakeholder group to influence the design of the network and make sure that impacts to fishermen would be reduced. In a Eureka focus group (2014), a fisherman said, "We are not happy with anything about the MLPA initiative. I'm very thankful that our stakeholders minimized the damage to the extent they did." A Shelter Cove fisherman (2014) reflecting on the process said, "I was pretty amazed actually that we had anything to say, any effect on anything.” North Coast fishermen reported that they were able to limit impacts from the MPA network because they learned from watching what unfolded in other regions. They observed the development of multiple stakeholder MPA proposals in other regions create a divide and conquer effect, so they sought to come together with other interest groups to create a unified proposal. One Eureka fishermen (2014) reported, "our stakeholder group had a remarkable achievement in achieving consensus between the fishermen and the environmentalists and the other people in the group and coming up with a unified proposal that did as little damage to fishing as they could get away with, and we had the advantage of seeing some of the things that went wrong in the other areas first, which helped.”

Despite the level of stakeholder influence reported, fishermen still had strong and sometimes scathing critiques of the MPA implementation process overall. Fishermen offered critiques that they did not believe the process adequately considered the context of North Coast region. A Eureka fisherman (2014) said, "one of the grievances that I think a lot of us have with the MLPAI is that they acted as though they were the first ones in town and there have never been restrictions on fishing before.” Fishermen lamented that the MLPA implementation process did not appear to consider and interact with existing fishing regulations, including numerous spatial closures such as rockfish conservation areas. Focus group participants felt that the MLPA process failed to consider the historical decline of the North Coast commercial and recreational fisheries. Captains reported that prior to MPA formation they had already experienced many restrictions and regulations that had severely constrained their fishing opportunities over the past two decades. Fishermen presented many stories of the decline in commercial and recreational fisheries and the cascading effects this had on fishing families, waterfront businesses, and waterfront infrastructure. A Fort Bragg fishermen (2014) reported that "there used to be 300-400 boats fishing out of this harbor, now there's 15-16 commercial salmon and crab boats.” A Crescent City fisherman (2014) echoed these sentiments saying, "In my fishery where there were 70 people doing what I did in mid-nineties, there is now 4 to 8 people...the last 2 months it has been 1 or 2 of us on a regular basis because of the way we've lost our infrastructure.” Finally, fishermen expressed concerns that the process did not consider the unique ecological context of 
the North Coast region. Fishermen felt that many of the guidelines for MPA implementation related to size, spacing, and habitat requirements were designed with the southern California context in mind and did not fit in the North Coast with its rocky coastline, lower fishing pressure, and areas of geographic isolation.

Participants also expressed concerns about what they saw as top-down elements to the process. Although the process was described as participatory, fishermen expressed concerns that many of the decisions about the MPA network - such as the science guidelines and the very need to implement MPAs at all - were made without public input prior to the process arriving in the region. As one Eureka fisherman (2014) described, "I think there's a consensus that it was a serious railroad job all the way through. But it basically said you're gonna come to an agreement, or we're doing it to you and we're gonna do it to you anyway, so you better come to an agreement that we agree with. There was very little latitude, very little room for creative thinking or input that might actually benefit the oceans, they had it all preconceived in their minds what they were gonna do.”

Participants reported feeling that although they had the opportunity to participate, their views were often dismissed. A Crescent City fisherman (2014) said, "When we participate, most of the time they don't believe anything we say” and a Fort Bragg fisherman (2014) said, "I told them things that I know for a fact, and they were not interested at all.” A statement from a Eureka fisherman (2014), summarizes feelings expressed by many fishermen that the effort to include local participation in the MPA planning process did not always feel genuine, "all they were doing was guiding us down that path to make us feel like we were involved. It was terrible." Lastly, fishermen expressed concerns about the public-private partnership behind the MPA initiative - "and the other thing is that whole thing was privately funded. How does that get off?" (Eureka Fisherman, focus group, 2014). As private money from the RLFF - a conservation group - funded parts of the MLPAI, fishermen expressed concerns that there could have been hidden agendas driving the planning process and outcomes.

\section{$\underline{6.0 \text { Discussion }}$}

Results from this study help to shed light on our three overarching research questions. With regard to our first question, results show that overall fishermen had negative perceptions of the process through which the MPA network was implemented. With regard to our second question, results reveal that fishermen have experienced some minor impacts from the network but most do not believe they will experience severe negative socioeconomic impacts. As a whole, fishermen also do not perceive that the MPA network will improve ocean health or their income from fishing. This discussion section will help to address research question number three by exploring reasons why fishermen may have perceived the MPA network and implementation process in the ways that they did.

These results deviate in surprising ways from the received wisdom in the scholarly literature regarding success of MPAs and social psychology. The literature on MPA success - particularly social success - highlights the importance of stakeholder participation and the equitable sharing of benefits and impacts (Christie 2004; Scholz et al. 2004; Dalton et al. 2012; Sayce et al. 2013). From the outside, it appears that the MPA planning process achieved these two factors. There 
were substantial avenues for stakeholder participation and impacts appear to have been well distributed - with fishermen not feeling that key fishing grounds were affected. However, social acceptance or satisfaction with the process overall was low among fishermen as $82 \%$ of respondents were dissatisfied, very dissatisfied, or neutral with the overall planning process.

Results also appear to belie expectations based on findings in the field of social psychology. The connection between "voice" - the inclusion of an opportunity to participate in a decision-making process - and "procedural fairness" - perceptions among participants the process was fair - is a robustly documented phenomenon, demonstrated in numerous laboratory and field studies (Lind et al. 1990). Quantitative and qualitative data show that stakeholders and fishermen had some semblance of a "voice" in the MPA planning process. Eighty percent of the respondents that we interviewed reported that they had participated in the MPA planning process for at least one day. Additionally, in the qualitative discussions, fishermen discussed how they were able to work within the stakeholder groups to influence the final design of the MPA network in a way that would limit impacts to fishermen. Yet, fishermen still reported low levels of satisfaction with the process $^{2}$. Qualitatively, they used terms such as “railroad job” that indicated perceptions of the process as less than fair. So the question remains: Why are participants in this MPA planning process acting in ways different than expected based on other findings in the literature? Why do fishermen have such negative views of an MPA planning process that limited impacts and provided opportunities for their voice to be incorporated? Results from this study point to three potential factors.

First, several study participants indicated that they felt successful stakeholder participation and influence occurred in spite of, not because of, the process. Although it was contrary to how the process was conducted in the other regions, stakeholders from the North Coast insisted on coming together and creating just one consensus proposal for MPA locations. In addition, contrary to other regions, RSG members on the North Coast decided to deviate from the Science Advisory Team guidelines for spacing and habitat representation in developing their MPA proposal (pers. comm., RSG members, 2014). A preliminary analysis revealed that due to the unique geography of the North Coast region, adhering to the SAT guidelines would leave little flexibility for where MPAs could be placed in and would almost certainly require the placement of MPAs in economically important waters, such as those near key ports (pers comm, RSG members, 2014). When the group came up with a unified proposal that limited impacts to fishermen and deviated from science guidelines - MLPA decision-makers were not able to weigh competing visions. They essentially had no choice but to accept that proposal, which they did with a few small modifications. Although fishermen may have ended up with a good outcome, many did not perceive that outcome as a result of how the planning process was designed. Rather they saw it as emerging from the community coming together to co-opt the process and make it work for them. This factor may also help to explain the divergent responses to the question about level of satisfaction with the inclusion of local input in the process and with the location of MPAs. Some respondents may have taken the end-result of the process at face value and considered how much input local stakeholders were able to have in the final MPAs, thus reporting satisfaction with that area. Others may have thought more complexly about the

\footnotetext{
${ }^{2}$ We did not ask participants if they thought the process was fair, just if they were satisfied with it overall. In addition, we did not specifically survey RSG members who were direct participants in the planning process and may have different views about it compared to commercial fishermen broadly.
} 
process and given more consideration to whether the process was really designed with the intention to meaningfully incorporate their input. Additionally, some fishermen may have been happy that MPAs were placed in locations that limited impacts on their livelihood, while others may have been upset that any MPAs were placed in the region at all.

Second, fishermen's perceptions of the MPA planning process could be related to the way that stakeholder participation was integrated into the process. Many key decisions about and guidelines for the MPA network were made at the state level before regional, participatory conversations began. Several fishermen stated that many of the state-wide guidelines did not fit well with the unique geography of the North Coast region and the guidelines left them with little room to be creative about where MPAs could be placed. North Coast fishermen may have been interested in participating in a discussion about whether additional MPAs were needed in the North Coast region at all. Some fishermen expressed concerns that the initiative did not appear to be designed to address a particular fishery resource or ecological need, but rather was focused on achieving conservation targets. Survey results indicate that the majority of North Coast regional fishermen did not agree with the premise that an MPA network was needed, or with the premises that the MPA network would improve ocean health or their future income from fishing. In their discussion about successful marine conservation, Lundquist \& Granek (2005) highlight the importance of "incorporating stakeholders at all phases of the process" (p. 1771). The fact that local participation was limited to the back-end of this MPA planning process may help explain some of the negative perceptions of the process.

Third, study results reveal the importance of trust to perceptions of marine conservation initiatives. In our analysis we uncovered a strong statistical relationship between the level of trust in the entity implementing the MPA network, and satisfaction with the overall MPA planning process, and with the final location of MPA networks. This suggests that trust in the implementing entity may be an important component to the overall social acceptability and success of MPAs. Trust is a complicated phenomenon. The literature on trust in natural resource processes may help explain why stakeholder trust in the North Coast marine management context is so low, as well provide insights for how trust could be improved.

Stern \& Coleman (2014) outline four key dimensions of trust, each of which may have played a key role in this case.

(1) Dispositional trust is based on personal histories and individual predispositions to trust or not in various situations. In this dimension, fishermen may inherently be predisposed to distrust marine conservation and management initiatives that could affect their livelihoods or have affected the livelihoods of previous generations of fishermen. This type of trust may help explain the fact that fishermen reported low levels of trust in the Ocean Protection Council, even though many of them did not know what the entity did. Based on the title alone fishermen assumed it was not trust-worthy. The close financial connections between the MLPAI and private conservation groups may also have served to reduce trust in the organization and process. Dispositional trust highlights the importance of subtle factors such as the branding, naming, and positioning of marine conservation initiatives. 
(2) Rational trust is based on evaluations of past experiences and outcomes. Under this dimension, low fishermen trust in the MLPAI may be linked to a history of negative interactions with marine conservation and management entities. In focus group conversations, fishermen described negative past experiences, such as times when they shared information with managers only to find that information to later be used against them. Rational trust also includes participants perceptions of the competence of those involved in the decision-making process. This form of trust may also explain fishermen's negative views about the scientists and the underlying science used in the implementation process. Repairing rational trust may require a commitment to developing a pattern of positive relationships between fishermen and managers overtime; making sure that key promises are kept. This could include working to build positive interactions both within and outside of key decisions. In the focus groups, several fishermen expressed an interest in collaborating with fishery scientists and managers on research efforts, so this could be a good place to start. Providing an opportunity for fishermen to collaborate with scientists and observe their approaches could also improve fishermen's perceptions of their competence.

(3) Affinitive trust is based on individual values and perceptions of shared identities. In this instance, low trust might be explained by the fact that fishermen simply did not see the conservation oriented professionals involved in the MLPAI as having the same values as them working class people who make their living off the ocean. The MLPAI was not advertised or designed to be a process that could ultimately help fishermen by securing important fish stocks and very few fishermen believed it would improve their income from fishing. Additionally, fishermen reported feeling that their views were sometimes dismissed during planning conversations. An actionable first step to moderating affinitive trust would be to impress on both parties the parallels in their values, which broadly revolve around the basic goal for healthy oceans and fish populations. Other studies have encountered similar findings and recommendations (Marino 2015; Gelcich et al. 2016; Johnson 2010).

(4) Procedural trust is based on individual interactions with institutional guidelines and monitoring mechanisms. Under this dimension, stakeholder distrust in particular entities or individuals could be moderated by the development of a process that all parties agree is fair. Accounts of the planning process by those who helped implement it show that great attention was made towards trying to make the process transparent, participatory, and fair (Fox et al. 2013). However, fishermen do not seem to have viewed the process in that way. In our results, we found evidence of procedural distrust among the fishermen including: many expressions that the process lacked transparency ("It didn't seem like there was a lot of transparency behind the agenda to me” - Focus group, Trinidad fisherman, 2014); concerns that many key decisions had been made before participation began; and concerns about the involvement of private funding and the potential for hidden agendas. Because procedural trust is related directly to the design and governance of management processes, it may be the form of distrust that managers have the most ability to address at present.

While some of the above identified dimensions of distrust may be easier to remediate than others, enhancing not just general trust but a diversity of these trust types will improve resource management's adaptive capacity to respond to and learn from inevitable conflicts (Stern \& Baird 2015). Achieving this will entail not only mitigating existing distrust, but also active 
demonstrations of trustworthiness from both parties into the future (Stern \& Baird, 2015). The social capital literature shows that development of trust both within and between groups involved in marine management can contribute to productive benefits, including economic progress (Dasgupta 2009).

\subsection{Conclusion:}

The California MLPA is a remarkable achievement for marine conservation. After over a decade of effort, and through the design of five regional processes that incorporated both scientific and stakeholder input, California enacted a network of 124 MPAs encompassing $16 \%$ of state waters (Kirlin 2013). However, it is just as important to learn from the process's shortcomings as it is to learn from its achievements. Findings from this study complicate several of the early assessments of the California MLPA which have championed the process as an overall success (Gleason et al. 2010; Fox et al. 2013; Kirlin et al. 2013). The literature on MPAs and success highlights the importance of examining both ecological and social factors. Qualitative statements combined with quantitative data reveal that on the whole commercial and CPFV fishermen in the North Coast were not satisfied with the MPA planning process and that many of these stakeholders continue to hold resentments about how the process was conducted. It is important to note that this study focused on two stakeholder groups: commercial and CPFV fishermen. Further research could examine perceptions of other groups such as Native American tribes, environmental groups, non-consumptive users, and local governments who were involved in or affected by the planning process and may have different views.

Future MPA managers and proponents can gain two important insights from this work. First, including participation in and of itself may not be not enough to make stakeholders satisfied with the process. Stakeholders may need to feel that requests for their input are genuine and that their perspectives will be heard. Additionally, it is important that stakeholder input be incorporated from the beginning of the process and not just near the end after many key decisions have been made.

Second, this study highlights the importance of trust to building successful and lasting marine conservation initiatives. Level of trust in the entity that implemented the MPA network correlated strongly with fishermen's satisfaction with the planning process and the MPA locations. Importantly, loss of trust from one planning process can spill over to other processes, creating challenges for future conservation initiatives. Building trust can be time-consuming, requiring on-the-ground work to develop relationships with communities and stakeholders. Targets or timelines for global MPA coverage can contribute a sense of urgency that may be antithetical to the trust-building that is necessary to ensure MPAs enjoy long-term social success and acceptability.

California, and likely many other coastal areas, may need to undertake additional efforts to improve trust between marine managers and resource users. If management entities set goals to build trust, then the changes in levels of trust could be monitored over time to assess improvement. Low levels of trust, however, may not be something that can be repaired overnight. Scholarship on trust tells us that even if there isn't standing trust when a process is 
initiated, process organizers can still work to build procedural trust by developing decisionmaking procedures that all parties view as fair. Building procedural trust into marine conservation efforts may be a starting point for developing a foundation of trust between stakeholders and managers that is necessary for successful marine conservation into the future.

\section{$\underline{\text { Acknowledgements }}$}

This publication was supported by the North Coast Marine Protected Areas Baseline Program, a collaborative effort among the California Ocean Protection Council, the MPA Monitoring Enterprise, a program of the California Ocean Science Trust, the California Department of Fish and Wildlife, and California Sea Grant under grant agreement \#R/MPA-36. The views expressed herein do not necessarily reflect the views of any of those organizations. Human subjects research was conducted under HSU IRB 13-002. We would like to thank the numerous fishermen who donated their time to participate in the study and share their views. Field staff members Laura Casali, Felicia Olmeta-Schult, Adriana Fintel, and Lorena Guerrero assisted the lead author with data collection. Our thanks to Justin Hospital for his help with the design of figures. 


\section{Literature Cited}

Badalamenti F, Ramos AA, Voultsiadoe E, Sanchez Lizaso JL, D’Aaaa G, Pipitone C, et al. (2000). Cultural and socio-economic impacts of Mediterranean Marine Protected Areas. Environmental Conservation. 27, 110-25.

Bauman C, Skitka L. (2009). Moral disagreements and procedural justice: Moral mandates as constraints to voice effects. Australian Journal of Psychology. 61(1), 40-49.

Bennett NJ, Dearden P. (2014). From measuring outcomes to providing inputs: governance, management, and local development for more effective marine protected areas. Marine Policy. 50, 96-110.

Bennett NJ. (2016). Use of perceptions to improve conservation and environmental management. Conservation Biology. 1, 1-5.

Boersma P, Parrish J. (1999). Limiting abuse: Marine Protected Areas, a limited solution. Ecological Economics. 31(2), 287-304.

CDFW. (2018). MPA Planning Process Historical Information. Accessed January 19, 2018. < http://www.dfg.ca.gov/marine/mpa/planningprocess.asp>

CDFW [map]. (2013). California North Coast MPAs. Marine Region GIS Lab. Last updated September 2013. <https://nrm.dfg.ca.gov/FileHandler.ashx?DocumentID=47582\&inline>

Carr LM, Heyman WD. (2012). It's About Seeing What's Actually Out There: Quantifying fishers' ecological knowledge and biases in a small-scale commercial fishery as a path toward co-management. Ocean and Coastal Management. 69, 118-132.

Caveen A, Polunin N, Gray T, Stead SM. (2014). The controversy over marine protected areas: Science meets policy. Springer.

Chen C, Lopez-Carr D. (2015). The importance of place: Unraveling the vulnerability of fisherman livelihoods to the impact of marine protected areas. Applied Geography. 59, 88-97.

Christie M. (2004). Marine protected areas as biological successes and social failures in Southeast Asia. American Fisheries Society. 42, 155-164.

Christie P. (2005). Observed and perceived environmental impacts of marine protected areas in two Southeast Asia sites. Ocean \& Coastal Management. 48, 252-270.

Cinner JE, Daw T, Huchery C, Thoya P, Wamukota A, Cedras M, Abunge C. (2014). Winners and losers in marine conservation: fishers' displacement and livelihood benefits from marine reserves. Society \& Natural Resources. 27, 994-1005. 
Claridge, T. (2004). Definitions of social capital. Social capital research.

Conway, Flaxen DL, Pomeroy C. (2006). Evaluating the Human - as well as the Biological - Objectives of Cooperative Fisheries Research. Fisheries. 31(9), 447-454.

Dalton T. (2005). Beyond biogeography: a framework for involving the public in planning of U.S. Marine Protected Areas. Conservation Biology. 19(5), 1392-1401.

Dalton T, Forrester G, Pollnac R. (2012). Participation, process quality, and performance of marine protected areas in the wider Caribbean. Environmental Management. 49, 12241237.

Dasgupta P. (2009). A matter of trust: Social capital and economic development. Annual Bank Conference on Development Economics, Korea 2009.

Davenport MA, Leahy JE, Anderson DH, and Jakes PJ. (2007). Building trust in natural resource management within local communities: A case study of the Midewin National Tallgrass Prairie. Environmental Management. 39(3), 353-368.

Deutsch, M. (2000). Justice and conflict. In M. Deutsch, \& P.T. Coleman (Eds.), The handbook of conflict resolution: Theory and practice. San Francisco: Jossey-Bass. 41-64.

Devine-Wright P, Howes Y. (2010). Disruption to place attachment and the protection of restorative environments: A wind energy cases study. Journal of Environmental Psychology. 30(3), 271-280.

Eagles PFJ, Romagosa F, Buteau-Duitschaever WC, Havitz M, Glover TD, McCutcheon B. (2013). Good governance in protected areas: an evaluation of stakeholders' perceptions in British Columbia and Ontario Provincial Parks. Journal of Sustainable Tourism. 21, 6079.

Folger, R. (1977). Distributive and procedural justice: Combined impact of "voice”' and improvement on experienced inequity. Journal of Personality and Social Psychology. 35, 108-119.

Fox E, et al. (2013). Enabling conditions to support marine protected area network planning: California’s Marine Life Protection Act Initiative as a case study. Ocean and Coastal Management. 74, 14-23.

Gelcich S, et al. (2016). Fishers' perception on the Chilean coastal TURF system after two decades: problems, benefits, and emerging needs. Bulletin of Marine Science. Vol 92.

Gleason M, et al. (2010). Science-based and stakeholder-driven marine protected area network planning: A successful case study from north central California. Ocean \& Coastal Management. 53, 52-68. 
Gleason M, et al. (2013). Designing a network of Marine Protected Areas in California: Achievements, costs, lessons learned, and challenges ahead. Ocean \& Coastal Management. 74, 90-101.

Hackett S, Richmond L, Chen C. (2017). Socioeconomics of North Coast Fisheries in the Context of Marine Protected Area Formation. Sea Grant report R/MPA-36. La Jolla: California Sea Grant College Program.

Hart D, Sissenwine MP. (2009). Marine reserve effects on fishery profits: A comment on White et al. 2008. Ecology Letters. 12, 2008-2010.

Hartley TW, Robertson R. (2006). Emergence of multi-stakeholder-driven cooperative research in the Northwest Atlantic: The case of the Northeast Consortium. Marine Policy. 30(5), 580-592.

Hartley TW, Robertson R. (2008). Cooperative research program goals in New England: Perceptions of active commercial fishermen. Fisheries. 33(11), 551-559.

Hough J. (1998). Obstacles to effective management of conflicts between national parks and surrounding human communities in developing countries. Environmental Conservation. 15(2), 129-136.

Jentoft S, van Son T.C., Bjorkan M. (2007). Marine protected areas: a governance system analysis. Human Ecology. 35(5), 611-622.

Johnson T. (2010). Cooperative research and knowledge flow in the marine commons: Lessons from the Northeast United States. International Journal of the Commons. 4(1), 251-272.

Kirlin J, Caldwell M, Gleason M, Weber M, Ugoretz J, Fox E, and Miller Henson M. (2013). California's Marine Life Protection Act Initiative: Supporting implementation of legislation establishing a statewide network of marine protected areas. Ocean and Coastal Management. 74, 3-13.

Klein C. J., Chan A, Kircher L, Cundiff A. J., Gardner N, Hrovat Y, et al. (2008). Striking a balance between biodiversity conservation and socioeconomic viability in the design of marine protected areas. Conservation Biology. 22(3), 691-700.

Leleu K, Alban F, Pelletier D, Charbonnel E, Letourneur Y, Boudouresque CF. (2012). Fishers' perceptions as indicators of the performance of Marine Protected Areas (MPAs). Marine Policy. 36, 414-422.

Lieberknecht L. (2008). Finding Sanctuary on tour: Lessons from the California Marine Life Protection Act (MLPA) and its implementation. Finding Sanctuary.

Lind, E. A., \& Tyler, T. R. (1988). The social psychology of procedural justice. New York: 
Plenum.

Lind, E. A., Kanfer, R., \& Earley, E. P. (1990). Voice, control, and procedural justice: Instrumental and non-instrumental concerns in fairness judgments. Journal of Personality and Social Psychology. 59, 952-959.

Lockwood M. (2010). Good governance for terrestrial protected areas: a framework, principles and performance outcomes. Journal of Environmental Management. 91, 754-766.

Lundquist CJ, Granek EF. (2005). Strategies for successful marine conservation: integrating socioeconomic, political and scientific factors. Conservation Biology. 19, 1771-8.

Marino, E. (2015). Cape Falcon Marine Reserve: A Pilot Study of Impacts, Outcomes and Effort Shift of Commercial and Charter Fishers. ODFW.

Masud M, Kari F. (2015). Community attitudes towards environmental conservation behavior: An empirical investigation within MPAs, Malaysia. Marine Policy. 52, 138-144.

McCay BJ, Jones P. (2011). Marine Protected Areas and the Governance of Marine Ecosystems and Fisheries. Conservation Biology. 12(6), 1130-1133.

McClanahan T, Davies J, Maina J. (2005). Factors influencing resource users and managers' perceptions towards marine protected area management in Kenya. Environmental Conservation. 32, 42-49.

McCreary, S. and E. Poncelet. (2006). Marine Life Protection Act Initiative: Facilitator's Report. Prepared by Concur under contract with the Marine Life Protection Act Initiative Contract Number: 2005-0059M. http://www.dfg.ca.gov/mlpa/pdfs/agenda_090606e.pdf

(NRC) National Research Council. (1997). Striking a balance: improving stewardship of marine areas. Washington, D.C., National Academy Press. pp. 177.

Osmond M, Airame S, Caldwell M, et al. (2010). Lessons for marine conservation planning: A comparison of three marine protected area planning processes. Ocean and Coastal Management. 53(2), 41-51.

Ordonez-Gauger, L., 2015. Assessing Fishermen's Perceptions of the Ecology and Management of the California North Coast Marine Protected Area Network. Masters Thesis Humboldt State University.

Pollnac RB, Crawford BR, Gorospe ML. (2001). Discovering factors that influence the success of community-based marine protected areas in the Visayas, Philippines. Ocean \& Coastal Management. 44(11), 683-710. 
Pomeroy C, et. al. (2011). California's North Coast Fishing Communities:

Historical Perspective and Recent Trends. California Sea Grant College

Program.

Raab, J. 2006. California Marine Life Protection Act: Evaluation of the Central Coast Regional Stakeholder Group Process. http://www.dfg.ca.gov/mlpa/pdfs/agenda_090606e.pdf

Richmond L, Kotowicz D. (2014). Equity and access in marine protected areas: The history and future of 'traditional indigenous fishing' in the Marianas Trench Marine National Monument. Applied Geography. XXX, 1-8.

Sayce K, Shuman C, Connor D, Reisewitz A, Pope E, Miller-Henson M, Poncelet E, Monie D, and Owens B. (2013). Beyond traditional stakeholder engagement: Public participation roles in California's statewide marine protected area planning process. Ocean and Coastal Management. 74, 57-66.

Scholz A, Bonzon K, Fujita R, Benjamin N, Woodling N, Black P, and Steinback C. (2004). Participatory socioeconomic analysis: drawing on fishermen's knowledge for marine protected area planning in California. Marine Policy. 28, 335-349.

Siegler, V. (2014). Measuring social capital. Measuring National WellObeing, Measuring Social Capital, July 2014.

Smith JW, Leahy JE, Anderson DH, Davenport. (2013). Community/ agency trust and public involvement in resource planning. Society and Natural Resources. 26, 452-271.

Stern M, Coleman KJ. (2014). The multidimensionality of trust: Applications in collaborative natural resource management. Society \& Natural Resources: An International Journal. 28, 117-132.

Stern M, Baird TD. (2015). Trust ecology and the resilience of natural resource management institutions. Ecology and Society. 20(2), 14.

Stewart R, Possingham H.P. (2005). Efficiency, costs and trade-offs in marine reserve system design. Environmental Modeling \& Assessment. 10, 203-213.

Sumaila U, Guenétte S, Alder J, et al. (2000). Addressing ecosystem effects of using areas. ICES Journal of Marine Science. 57, 752-760.

Voyer M, Gladstone W, Goodall H. (2012). Methods of social assessment in marine protected area planning: is public participation enough? Marine Policy. 36(2), 432-439.

Webb EL, Mailiao R, Siar SV. (2004). Using local user perceptions to evaluate outcomes 
of protected area management in the Sagay Marine Reserve, Philippines. Environmental Conservation. 31,138- 148

Wolff M. (2015). From sea sharing to sea sparing - Is there a paradigm shift in ocean management? Ocean and Coastal Management. 116, 58-63.

Woolcock M. (1998). Social capital and economic development: Towards a theoretical synthesis and policy framework. Theory and Society. 27, 151-208. 